\title{
Comparison the Oral Candida Carriage in Type 2 Diabetic and Non Diabetics
}

\author{
Abbas Ali Jafari ${ }^{1}$, Elham Khanpayah ${ }^{2}$, Hakimah Ahadian ${ }^{3,}$ \\ ${ }_{1}^{1}$ Medical Parasitology and mycology Department, Medical School, Shahid Sadoughi University of Medical Sciences,Yazd, IR Iran \\ 2 Department of Orthodontics, Dentistry School, Shahid Sadoughi University of Medical Sciences, Yazd, IR Iran \\ 3 Department of Oral Medicine, Dentistry School, Shahid Sadoughi University of Medical Sciences, Yazd, IR Iran \\ ${ }^{*}$ Corresponding author: Hakimah Ahadian, Oral medicine Department, Dentistry school, Shahid Sadoughi University of Medical Sciences, Yazd, IR Iran. Tel: +98-3516255881, E-mail: \\ drahadian@ssu.ac.ir. \\ Received: October 09, 2012; Revised: January 11, 2013; Accepted: February 17, 2013
}

Keywords: Candida albicans; Diabetes Mellitus

\section{Dear Editor}

Diabetes mellitus is a common and global epidemic in the new millennium, which is strongly related to lifestyle and economic change, caused chronic hyperglycemia with impairment of carbohydrate, lipid and protein metabolism resulting from defects in insulin secretion and action. The World Health Organization (WHO) has expected an increasing development of diabetes to more than 300 million by the year 2025; particularly, with type 2 diabetes mellitus (1). However, T2DM was known as an adult-onset of diabetes in the past, but it has dramatically increasing more recently in young people and known for about $90 \%$ of the global incidence of diabetes and its complications (2).

Candida infections, in particular, oral candidiasis has also been frequently recognized in diabetic patients, which can be due to their increased glucose in their oral fluids and their immune dysfunction $(3,4)$. Environmental alteration of diabetic oral cavity favors of Candida colonization and cause a change from the harmless commensally existence to a pathogenic state that known as predisposing factors for Candida infection. In this study, we compare the oral Candida carriage rate of 40 diabetic and 40 non diabetic by culture of their saliva samples and performing colony forming unit technique.

Our data showed a higher oral Candida carriage rate in type two diabetics in compare with the non-diabetic control group (Table 1). Spearman correlation test also showed statistically significant differences between the duration of diabetes and colonization of Candida albicans in their saliva $(P=0.0341)$, however there wasn't seen any correlation between fasting blood-glucose level and oral Candia colonization in diabetic group $(\mathrm{P}=0.512)$.

Different oral Candida carriage rates were reported in most studies, which could be as a result of different sampling procedures (such as, whole saliva collection, swabs, water and buffer rinsing and etc) used by different investigators. The whole saliva sample collection and colony forming unit (CFU) technique used in present study is a sensitive technique, which is usually used for estimating the oral Candida carriage and also for clinical diagnosis of oral candidiasis $(3,4)$. Current study has affirmed that Candida colonization is more prevalent in the oral cavity of type 2 diabetics than non-diabetics subjects as reported by various studies (5-7). There wasn't seen any association between FBS level and oral Candida colonization in type 2 diabetics saliva however Khosravi et al. reported a significant relationship between oral yeast density of diabetic patients and their fasting blood glucose level (8). A higher colonization of Candida in diabetics with longer history of diabetes was seen $(P=0.0341)$, which supported by few other similar studies $(5,9,10)$. Results of present study indicated a higher oral Candida carriage in type 2 diabetics and recommended more attention for controlling of diabetes.

Implication for health policy/practice/research/medical education:

Results of present study indicated a higher oral Candida carriage in type 2 diabetics and recommended more attention for controlling of diabetes.

Copyright (C) 2013, Ahvaz Jundishapur University of Medical Sciences; Licensee Kowsar Ltd. This is an Open Access article distributed under the terms of the Creative Commons Attribution License (http://creativecommons.org/licenses/by/3.0), which permits unrestricted use, distribution, and reproduction in any medium, provided the original work is properly cited. 


\begin{tabular}{|c|c|c|c|}
\hline Subjects & $\begin{array}{l}\text { No. of Cases With Oral Can- } \\
\text { dida Carriage }\end{array}$ & $\begin{array}{l}\text { No. of Cases Without Oral- } \\
\text { Candida Carriage }\end{array}$ & Total \\
\hline \multicolumn{4}{|l|}{ Non-diabetic } \\
\hline Female & $5(23.8)$ & $16(76.2)$ & 21 \\
\hline Male & $4(21.05)$ & $15(78.95)$ & 19 \\
\hline Total & $9(22.5)$ & $31(77.5)$ & 40 \\
\hline \multicolumn{4}{|c|}{ Type 2 Diabetic } \\
\hline Female & $11(55)$ & $9(45)$ & 20 \\
\hline Male & $13(65)$ & $7(35)$ & 20 \\
\hline Total & $24(60)$ & $16(40)$ & 40 \\
\hline
\end{tabular}

\section{Acknowledgements}

The authors would like to thank Dr Afkhami and his personnel of Diabetes research centre for their cooperation in sample collection and also Farzaneh Mirzaei for her kind help in the laboratory works.

\section{Authors' Contribution}

None declared.

\section{Financial Disclosure}

None declared.

\section{Funding/Support}

This work is a part of a dentistry student thesis (no 383), which supported by Deputy of research from Shahid Sadoughi University of Medical Sciences.

\section{References}

1. $\quad$ Diabetes--a global threat. Lancet. 2009;373(9677):1735.

2. WHO Technical Report Series. Prevention of diabetes mellitus; Geneva: WHO Publications; 1994.

3. Sahin I, Oksuz S, Sencan I, Gulcan A, Karabay O, Gulcan E, et al. Prevalance and risk factors for yeast colonization in adult diabetic patients. Ethiop Med J. 2005;43(2):103-9.

4. Samaranayake LP, MacFarlane TW. Host factors and oral candidosis. Oral candidosis. 1990:66-103.

5. Bai KY, Reddy CD, Abu-Talib SH. Oral candidal carriage in young insulin dependent diabetics. I Indian Soc Pedod Prev Dent. 1995;13(1):20-3.

6. Kumar BV, Padshetty NS, Bai KY, Rao MS. Prevalence of Candida in the oral cavity of diabetic subjects. J Assoc Physicians India. 2005;53:599-602.

7. Willis AM, Coulter WA, Fulton CR, Hayes JR, Bell PM, Lamey PJ. Oral candidal carriage and infection in insulin-treated diabetic patients. Diabet Med.1999;16(8):675-9.

8. Khosravi AR, Yarahmadi S, Baiat M, Shokri H, Pourkabireh M Factors affecting the prevalence of yeasts in the oral cavity of patients with diabetes mellitus. JMed Mycol. 2008;18(2):83-88.

9. Lotfi-Kamran MH, Jafari AA, Falah-Tafti A, Tavakoli E, Falahzadeh $\mathrm{MH}$. Candida Colonization on the Denture of Diabetic and Nondiabetic Patients. Dent Res J(Isfahan). 2009;6(1):23-7.

10. Tekeli A, Dolapci I, Emral R, Cesur S. Candida carriage and Candida dubliniensis in oropharyngeal samples of type-1 diabetes mellitus patients. Mycoses. 2004;47(7):315-8. 